\title{
Potential of anti-inflammatory treatment for cystic fibrosis lung disease
}

\author{
This article was published in the following Dove Press journal: \\ Journal of Inflammation Research \\ 5 August 2010 \\ Number of times this article has been viewed
}

\author{
Jennifer L Taylor-Cousar ${ }^{1,2}$ \\ Kelsey A Von Kessel ${ }^{2}$ \\ Robert Young' \\ David P Nichols 1,2 \\ 'Department of Medicine, National \\ Jewish Health, Denver, Colorado, USA; \\ ${ }^{2}$ Department of Pediatrics, National \\ Jewish Health, Denver, Colorado, USA
}

\begin{abstract}
Cystic fibrosis (CF) is the most common life-shortening genetic disorder in Caucasians. With improved diagnosis and treatment, survival has steadily increased. Unfortunately, the overwhelming majority of patients still die from respiratory failure caused by structural damage resulting from airway obstruction, recurrent infection, and inflammation. Here, we discuss the role of inflammation and the development of anti-inflammatory therapies to treat CF lung disease. The inflammatory host response is the least addressed component of $\mathrm{CF}$ airway disease at this time. Current challenges in both preclinical and clinical investigation make the identification of suitable anti-inflammatory drugs more difficult. Despite this, many researchers are making significant progress toward this goal and the CF research community has reason to believe that new therapies will emerge from these efforts.
\end{abstract}

Keywords: therapy, cystic fibrosis, survival, inflammation

\section{Introduction}

Cystic fibrosis (CF) is an autosomal recessive disease caused by mutations on chromosome 7 resulting in impaired chloride transport through the cystic fibrosis transmembrane conductance regulator (CFTR) protein. ${ }^{1}$ In exocrine glands, this channel is concentrated in the apical membrane of epithelial cells and helps to regulate ion and water content at the luminal surface. For reasons that are not completely understood, CFTR deficiency causes greater activity of the epithelial sodium channel (ENaC) leading to increased absorption of sodium and water from the luminal surface. In the lung, this dysfunctional conductance of chloride and sodium ions reduces the water content and height of the airway surface liquid layer (ASL). An abnormal ASL impairs the mucociliary escalator causing accumulation of tenacious secretions within the airways. These secretions trap bacteria and other pathogens and initiate a self-perpetuating cycle of airway obstruction, endobronchial infection, and exuberant inflammation. It is not clear whether or not exuberant inflammation in the human CF airway exists independent of airway obstruction and infection. Regardless, evidence indicates that the inflammatory host response in the airway begins early in life, is of greater magnitude than is observed in patients without CF and persists beyond apparent eradication of infectious stimuli. ${ }^{2-8}$

For many years, regular use of pancreatic enzyme supplements and improved nutrition have greatly improved health outcomes for patients with CF. Therefore, pulmonary manifestations are currently the center of health impairment for most of these patients. For over 40 years, prescribed therapies have focused on improving
Correspondence: David P Nichols Departments of Pediatrics and Medicine, National Jewish Health, University of Colorado Health Sciences Center, I 400 Jackson Street, K 1026 Denver, CO 80206, USA

Email nicholsd@njhealth.org 
airway clearance of secretions and treating endobronchial infection. However, in recent decades, there has been a growing appreciation of the role of inflammation in CF lung disease. Excessive airway inflammation is a key component of the pathophysiology of $\mathrm{CF}$, and researchers are working to identify effective and well-tolerated anti-inflammatory therapies.

Both prospective and retrospective studies of antiinflammatory medications in CF demonstrate preserved lung function measured by spirometry - a value closely correlated with survival. ${ }^{9-14}$ The majority of these studies do not show an increased risk of infectious complications in subjects receiving anti-inflammatory drugs. This paper reviews these studies, as well as ongoing research addressing the negative impacts of airway inflammation in CF.

\section{Inflammation in CF lung disease}

At birth, the lungs of neonates with $\mathrm{CF}$ are structurally normal and not inflamed. However, during early infancy, secretions begin to plug the bronchioles and ducts of submucosal glands. ${ }^{2}$ Bronchoalveolar lavage (BAL) studies from infants with CF show high concentrations of neutrophils and proinflammatory mediators in the airways, often in the absence of identifiable pathogens. ${ }^{3,6,7}$ When bacteria are found, the inflammatory response relative to the bacterial burden is greater in CF infants compared with infants without $\mathrm{CF}^{8,15}$ This neutrophil dominated host response is typically sequestered in and around the airways but spreads to involve the local airway wall and supporting structures in advanced stages. The alveoli are spared until late in the disease course, making CF largely an airways disease. The upper limit of normal for BAL from healthy lung is $<3 \%$ neutrophils. BAL from CF lungs typically contains 10 , or even 20 times this degree of neutrophilia (Figure 1).

In addition to being excessive, the inflammatory response is also prolonged, leading many researchers to postulate that the exaggerated inflammatory state is largely a function of impaired resolution. This may explain why inflammation can be detected in apparently sterile BAL samples of infants with $\mathrm{CF}$, reflecting an ongoing response to prior infection. ${ }^{3} \mathrm{As}$ it is central to the host inflammatory response in the CF airway, anti-inflammatory therapies must address, either directly or indirectly, the neutrophil itself or its products.

\section{Nuclear factor kappa-B transcriptional regulation}

Many believe that the heightened inflammatory response in CF is closely related to abnormal CFTR function. This theory is supported by data showing increased basal and inducible inflammation in human airway cells with either genetic or chemical CFTR impairment and decreased inflammatory response in CF epithelial cells treated with CFTR correctors. ${ }^{16,17}$ Likewise, transgenic mice with CFTR impairment show altered inflammatory response to pertinent airway challenge when compared with wild-type mice. ${ }^{18,19}$ Much of the mechanistic research has focused on

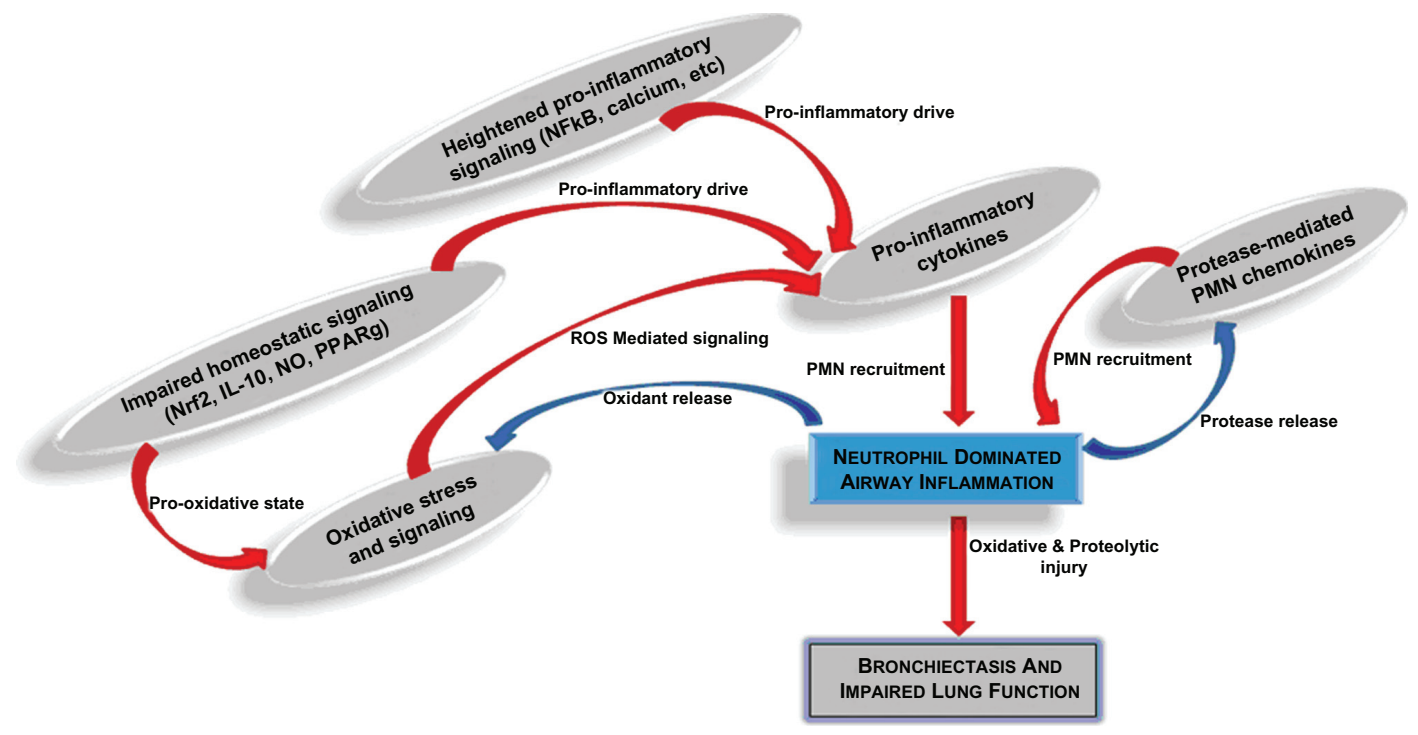

Figure I Complex interactions contributing to CF airway inflammation. Several proinflammatory mechanisms have been identified in research of cystic fibrosis (CF) airway disease. Heightened proinflammatory signaling pathways, impaired redox-regulation and anti-inflammatory signaling pathways, and perpetual proteolytic and oxidative stress are some of the most well-described mechanisms driving the neutrophil-dominated host response. This neutrophilic inflammation, along with ineffective airway clearance and chronic airway infection, lead to progressive bronchiectasis and impaired lung function.

Abbreviations: PMN, polymorphonuclear cell, ie, neutrophil; ROS, reactive oxygen species; NO, nitric oxide. 
the intracellular transcription factor nuclear factor kappa-B $(\mathrm{NF} \kappa \mathrm{B})$. The majority of proinflammatory cytokines believed to be important in CF-related airway inflammation are regulated by $\mathrm{NF} \kappa \mathrm{B}$ activity. These include interleukin (IL)-8, tumor necrosis factor-alpha (TNF- $\alpha$ ), IL-1 $\beta$, IL-6, and granulocyte-macrophage colony-stimulating factor, and so on. ${ }^{4}$ Cellular interaction with bacteria, bacterial products, and proinflammatory cytokines causes NFאB to translocate to the nucleus and promote transcription of multiple proinflammatory gene products. It is unclear whether or not this transcription factor is inherently altered in $\mathrm{CF}$. The observed increase in $\mathrm{NF} \kappa \mathrm{B}$ activation may be a response to the abundant stimuli present in the CF lung. Alternatively, there is evidence of increased Iא-kinase (IKK) activity in CFTR-deficient epithelial cells. IKK is an important step in the canonical activation pathway for $\mathrm{NF} \kappa \mathrm{B}$ and over activity of this enzyme would increase $\mathrm{NF} \kappa \mathrm{B}$-driven proinflammatory signaling. ${ }^{20-22}$

Studies also suggest that the local environment of airway secretions surrounding CF respiratory epithelial cells enhances NFKB activation by increasing local calciumdependant signaling of this transcription factor. ${ }^{23}$ These data would indicate that improved airway clearance can indirectly reduce inflammation in the CF airway. Similarly, inflammatory products (eg, DNA from necrotic neutrophils, mucus production) add to the viscosity of airway secretions and further impair airway clearance. Therefore, impaired airway clearance and the exaggerated inflammatory state in the CF airway are closely linked. Effective therapies for either abnormality will likely improve both aspects of CF lung disease. Furthermore, whether or not increased activation of NFKB is a primary or secondary process in $\mathrm{CF}$ cells, its central role as a regulator of many downstream inflammatory responses makes it an obvious target for antiinflammatory treatment.

\section{Anti-inflammatory signaling}

Studies indicate that other immunoregulatory signaling pathways may be abnormal in CF. IL-10, an important antiinflammatory cytokine produced by many cell types in the lung is reduced. ${ }^{24,25}$ Lipopolysaccharide (LPS) and TNF- $\alpha$, which are abundant in the CF airway, stimulate IL-10 production in subjects without $\mathrm{CF}^{26}$ However, studies of BAL from patients with CF unexpectedly contain relatively little IL-10 as compared with that from patients without $\mathrm{CF}^{4,27}$ Both IL-10 and nitric oxide (NO), which is also low

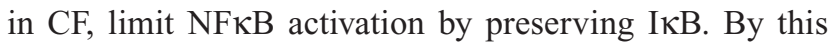
and other mechanisms, mediators such as IL-10 induce neutrophil apoptosis, decrease antigen presentation and T-cell stimulation, and help to terminate the inflammatory response. ${ }^{28,29}$ Therefore, impairment of such immunoregulatory signaling may contribute to both the heightened and prolonged airway inflammatory response.

PPAR $\gamma$ is a transcription factor that, among other functions, also limits NFKB activity and is reduced in CF human airway epithelial cells. ${ }^{30,31}$ Abnormalities in the fatty acid content of CF cells, with deficiencies of both docosahexaenoic acid (DHA) and linoleic acid, may contribute to impaired PPAR $\gamma$ signaling. ${ }^{30}$ Similarly, lipoxin A4 (LXA4) is an important endogenous anti-inflammatory lipid mediator that helps mitigate the acute inflammatory response. ${ }^{32}$ It has been reported that LXA4 concentrations are reduced in BAL fluid from stable CF patients compared with non-CF patients with pulmonary inflammation. ${ }^{32}$ Although the reasons for the decreased LXA4 concentrations have not been elucidated, administration of a metabolically stable lipoxin analog in cell culture and mouse models of chronic airway infection and inflammation decreased IL-8 production and neutrophilic inflammation without increasing infectious burden. ${ }^{32}$ The role of LXA4 deficiency in CF lung disease remains controversial and a more recent study found no difference in LXA4 concentration in BAL from CF patients compared with non-CF disease-matched controls with neutrophilic airway inflammation. ${ }^{33}$

\section{T helper 17}

Recent work proposes a greater role for adaptive immunity in $\mathrm{CF}$ as a subset of $\mathrm{T}$ cells known as $\mathrm{T}$ helper (TH)-17 cells appear to be involved in CF pulmonary inflammation. ${ }^{34}$ IL-23 and IL-17 are proinflammatory cytokines involved in TH-17 cell signaling and are elevated in CF airways (human and mouse) in response to common stimuli. ${ }^{35,36}$ IL-17 appears to prime CF airway epithelial cells to greater IL- 8 release in response to Pseudomonas, and may promote MUC5AC gene transcription through NF $\kappa B$ activation. ${ }^{37,38}$ Viscous secretions at the apical surface of airway epithelia trap bacteria and may magnify the likelihood of antigen presentation to dendritic cells and macrophages which, in turn, trigger the IL-23/IL-17 signaling pathway. IL-17 is important in recruiting neutrophils to the airway in response to bacterial products such as LPS and the relative importance of IL-17 in the CF airway is a focus of continued research. ${ }^{39}$ These findings further support the interconnected nature of impaired airway clearance, bacterial infection, and inflammatory response. 


\section{Nrf2 transcriptional regulation}

Finally, recent studies in CF cell and mouse models have uncovered a deficiency of nuclear factor E2-related factor 2 (Nrf2), a transcription factor functional in respiratory epithelia and pivotal to mitigating the acute inflammatory response. ${ }^{40} \mathrm{Nrf2}$ regulates a large number of antioxidant and cytoprotective genes. Therefore, impairment of this transcription factor may underlie both the prooxidative and hyperinflammatory state. Several studies find an increased oxidative state in the $\mathrm{CF}$ airway, and reactive oxygen species, as intracellular messengers, are complicit in NFKB activation in respiratory epithelia. ${ }^{41}$ Data from CF models show low levels of NO resulting from a deficiency of inducible NO synthase in epithelial cells, ${ }^{42,43}$ and low concentrations of glutathione in extracellular lining fluid, possibly due to deficient transport of this antioxidant through CFTR channels. ${ }^{44,45}$ Many prooxidative and inflammatory signaling pathways are interrelated and, therefore, compounds with direct or indirect antioxidant properties may be effective anti-inflammatories. In support of this theory are data showing that Nrf2 agonists reduce the airway inflammatory response in CF cell and mouse models, making Nrf2 signaling and antioxidant gene regulation another promising area for therapeutic development. ${ }^{46}$

Experiments utilizing Nrf2-knockout mice and bone marrow adoptive transfer show that Nrf2 function in the airway plays a pivotal role in both inflammatory response and structural damage after elastase-induced injury. ${ }^{47}$ A significant protease/antiprotease imbalance exists in the CF airway, largely driven by excess free neutrophil elastase. This not only is a major contributor to progressive airway damage, but also likely helps to perpetuate the neutrophilic inflammatory response. Certain proteases (eg, MMP-8, MMP-9) abundant in the CF airway are capable of cleaving small peptides from collagen. ${ }^{48}$ These peptides can then serve as chemoattractants for neutrophil recruitment to the airway, demonstrating an important role of proteases in the inflammatory host response. Though further increased during pulmonary exacerbation, protease levels in the $\mathrm{CF}$ airway typically remain elevated even during times of relative health. Recent work highlights the ability of neutrophil elastase to cleave and activate MMP-9 while cleaving and inactivating its inhibitor TIMP-1. ${ }^{49}$ This reaffirms the neutrophil and its products as a central regulator and therapeutic target in the excessive and perpetual inflammatory state. Similarly, 2 neutrophil serine protease inhibitors, secretory leukoprotease inhibitor and elafin, are both cleaved and inactivated by abundant neutrophil elastase in the infected CF airway. ${ }^{50,51}$
In addition to augmenting the proteolytic imbalance, elastase also impairs the antimicrobial host defense properties of these proteins, again underscoring the need to address excessive inflammation in a comprehensive treatment strategy.

Ultimately, there is evidence that many altered immunoregulatory pathways contribute to the inflammatory response in CF. Although no unified pathway directly connecting CFTR dysfunction to exuberant inflammation has been found, the combined effects of numerous dysregulated proinflammatory and anti-inflammatory signaling events are a significant part of the pathophysiology in CF lung disease. It may ultimately be less important to determine whether this is directly related to CFTR impairment or more indirectly due to the altered airway environment developing from both abnormal CFTR and ENaC channel activity. Despite inconsistencies in preclinical models, the majority of the $\mathrm{CF}$ research community view inflammation as a valid therapeutic target. This view is supported by greater lung health afforded from either systemic corticosteroids or high-dose ibuprofen in clinical trials. ${ }^{10,11,13}$ However, neither of these wellstudied anti-inflammatories is prescribed for the majority of patients with CF secondary to concern over unacceptable side effects. ${ }^{52}$ Therefore, research continues to search for more suitable agents that will likely benefit the majority of patients with $\mathrm{CF}$ by addressing a fundamental component of ongoing airway injury.

\section{Prior clinical trials of anti-inflammatory therapy in CF Corticosteroids}

Though several potential anti-inflammatory drugs have been studied in clinical trials of patients with CF, results from prior trials with 3 medications largely drive this field of research: systemic corticosteroids, high-dose nonsteroidal anti-inflammatory drugs (NSAIDs), and azithromycin. Nearly 3 decades ago, investigators noted that patients with $\mathrm{CF}$ who also had hypogammaglobulinemia treated with systemic corticosteroids had better lung function than those without hypogammaglobulinemia (and therefore not treated with steroids). ${ }^{53}$ This led to 2 large clinical trials of oral steroids in patients with CF. An initial study enrolled 21 patients aged 1-12 years with mild to moderate lung disease, given with either placebo or prednisone $1-2 \mathrm{mg} / \mathrm{kg}$ by mouth every other day. ${ }^{9}$ Subjects receiving prednisone showed better lung function, improved weight gain, and few hospitalizations over a 4-year observational period. No apparent adverse events were reported during this study, which led to a larger, multicenter trial, enrolling 
285 patients aged 6-14 years with mild to moderate lung disease. ${ }^{54}$ Prednisone $1 \mathrm{mg} / \mathrm{kg}$ or $2 \mathrm{mg} / \mathrm{kg}$ by mouth every other day was compared with a placebo group, and again showed beneficial effects of corticosteroids on lung function - particularly in subjects infected with Pseudomonas aeruginosa. However, significant adverse events occurred in those receiving prednisone, including growth impairment, cataracts, and glucose intolerance. The high-dose ( $2 \mathrm{mg} / \mathrm{kg}$ ) group was halted half way through the 4-year study due to a high incidence of adverse events. ${ }^{55}$ Follow-up analysis 6 years after completion of the trial found persistent growth deficits, ${ }^{56}$ and a separate analysis 5 years after the initial smaller study found growth deficits in $14 / 17$ subjects in the prednisone arm who completed the study. ${ }^{12}$ For these reasons, regular use of systemic corticosteroids is not recommended for patients with $\mathrm{CF}$, despite the beneficial effects on pulmonary health. It is, however, worth noting that those receiving prednisone in these trials did not show greater risk of infection. Though unacceptable as a long-term therapy for most patients, shorter courses of systemic steroids may be useful, ${ }^{57}$ particularly for those with a prominent asthmatic phenotype or during treatment for acute pulmonary exacerbation when the inflammatory response is further increased.

The use of inhaled corticosteroids (ICS) to treat CF lung disease has been a topic of much interest in recent years. This therapy continues to be prescribed to a large number of patients, likely due to a relatively high incidence of asthmalike symptoms in patients with CF and the perceived safety and familiarity among health care providers. However, in clinical trials subjects with CF, ICS have not consistently proven effective. A recent Cochrane Database Systematic Review of clinical trials found no conclusive benefits of ICS in $\mathrm{CF}$ and no apparent adverse events when discontinuing ICS. ${ }^{58}$ Authors also noted that data are not available to determine if long-term use of ICS will reduce lung inflammation in $\mathrm{CF}$, and that this question is unlikely to be answered by a clinical trial at this point.

\section{lbuprofen}

Seeking to identify an anti-inflammatory drug that might be better tolerated, Konstan et $\mathrm{a}^{59}$ in Cleveland began studying the use of high-dose ibuprofen in animal models, and then in clinical trials of patients with CF. A 4-year double-blind placebo-controlled trial in 85 subjects aged 5-39 years with mild lung disease showed that those receiving the NSAID had less decline in pulmonary function, preserved body weight, and fewer hospitalizations. ${ }^{11}$ Individual pharmacokinetics targeting a peak plasma concentration of $50-100 \mu \mathrm{g} / \mathrm{mL}$ (typical dose $20-30 \mathrm{mg} / \mathrm{kg}$ ) were used in this study. This is 2-3 times higher than commonly prescribed doses and in vitro studies indicate that, at this concentration, ibuprofen may inhibit pertinent proinflammatory signaling events in the cell (ie, NFkB, AP-1 activation). ${ }^{60,61}$ A second trial was conducted in Canada with 142 subjects over 2 years and showed preserved forced vital capacity and a trend toward preserved forced expiratory volume in 1 second $\left(\mathrm{FEV}_{1}\right)$ in the ibuprofen arm compared with placebo. ${ }^{13}$ The incidence of adverse events between placebo and ibuprofen did not significantly differ in these trials, and in the Canadian study a greater number of subjects receiving placebo dropped out of the study due to adverse events that could be attributable to NSAID therapy. This observation likely underscores the reason that fewer than $10 \%$ of patients with CF in the United States currently receive high-dose ibuprofen. The underlying disease often manifests with symptoms that overlap with NSAID toxicity (eg, abdominal pain, epistaxis, hemoptysis, gastrointestinal hemorrhage) and confusion or concern of these apparently rare, though at times dramatic, events is the reason most cited by practitioners for not prescribing this therapy. ${ }^{52}$ The need for individual pharmacokinetics has also been cited as a limitation to ibuprofen use.

\section{Azithromycin}

Azithromycin is a commonly prescribed therapy for $\mathrm{CF}$ and likely has immunomodulatory effects. Data indicating that regular use of macrolides afforded better pulmonary health in another chronic lung disease, diffuse panbronchiolitis, led to studies in CF, including a trial of azithromycin in 185 patients with $\mathrm{CF}$ who had mild to moderate lung disease and were infected with $P$. aeruginosa.$^{62}$ This multicenter, placebocontrolled trial found that subjects given azithromycin thrice weekly had better lung function, weight gain, quality of life, and fewer pulmonary exacerbations than those given placebo. Studies conducted in the United States and abroad similarly showed that chronic azithromycin provides clinically relevant health benefits, though more consistently so in those infected with $P$. aeruginosa. ${ }^{63,64}$ Many mechanistic studies have since been done to better understand how azithromycin is beneficial. From data available to date, it appears that there is a combined effect of both anti-inflammatory and antiinfective properties. Azithromycin can inhibit neutrophil recruitment and oxidative burst, as well as proinflammatory cytokine production. ${ }^{65-67}$ This macrolide antibiotic also inhibits several virulence factors of $P$. aeruginosa, which may be more susceptible to azithromycin in the stationary growth 
phase. ${ }^{68}$ The question of mechanism is further complicated by recent studies in both CF mouse and human models showing that treatment with azithromycin causes increased rather than decreased release of pivotal proinflammatory cytokines from primary airway epithelial cells. ${ }^{69,70}$ Similarly, sputum concentrations of IL-8 were not significantly altered in the largest US clinical trial of azithromycin in CF patients and patients receiving this treatment continue to have significant airway neutrophilia. ${ }^{62}$

Though not always reflected in spirometry, the clinical benefits of azithromycin therapy in CF appear to be significant. However, the complexities noted above combined with an increased incidence of nausea and vomiting and increased antibiotic resistance ${ }^{71}$ (eg, Staphylococcus aureus, nontuberculous mycobacteria) with chronic use, lead many to conclude that this therapy is useful but not the ideal antiinflammatory treatment for CF. Recent data from a large clinical trial suggest that azithromycin use for 24 weeks may not significantly affect pulmonary function in children without chronic P. aeruginosa infection. ${ }^{72}$ Despite the fact that $\mathrm{FEV}_{1}$, the primary outcome measure, was not affected, other potentially important exploratory outcomes were improved with azithromycin use (eg, rate of pulmonary exacerbation).

There are many challenges to identifying a more suitable anti-inflammatory therapy. Despite what has been learned from prior research, the proper molecular targets are not clear and there is significant redundancy in proinflammatory signaling within the lung. Highly specific drugs targeting individual pathways have often proven ineffective or potentially toxic. Those with the greatest proven clinical efficacy appear to have broad, rather nonspecific effects, which may predispose to more side effects. Despite these challenges, ongoing research is identifying multiple new and promising therapeutic targets, and there is significant hope that more effective and welltolerated therapies will be identified in the near future.

\section{Challenges in preclinical models when testing new therapies}

An essential step in developing new anti-inflammatory therapies is use of preclinical models to identify molecular targets and test drug activity. Although these models have provided fundamental information for our understanding of the role of inflammation in CF lung disease, each model under current use has limitations for the evaluation of candidate therapies. Available cell culture and animal models are unable to reproduce the chronic airway impaction and infection underlying the perpetual inflammatory response. As highlighted earlier, the interrelated nature of multiple processes in the CF airway (chronic infection, airway obstruction, and host inflammatory response) is clear. Therefore, improved methods, likely employing better animal models, will be necessary to more accurately predict clinical utility when testing promising candidate therapies.

\section{Cell lines and cultured epithelial cells}

A comprehensive list of established cell lines used in CF research is beyond the scope of this article, but has been reviewed. ${ }^{73}$ Use of immortalized cell lines from patients with CF has been especially useful to study the effects of CFTR dysfunction and to test drugs that may improve CFTR function. ${ }^{73,74}$ Some features of the CF inflammatory response have been demonstrated in primary and immortalized CF cells, such as an increased inflammatory response following P. aeruginosa exposure, ${ }^{75,76}$ and higher levels of proinflammatory cytokines and nuclear transcription factors involved in the inflammatory pathway. ${ }^{25,77-80}$ However, it is unlikely that the immunologic response to chronic bacterial infection seen in the CF lung can be fully reproduced in either cultured primary cells or in immortalized cell lines. For example, phenotypic characteristics that are expressed by a particular clone from an immortalized cell line may not completely reflect that of the original mixed population of epithelial cells from which it was derived. Furthermore, the transformation process and cell passaging (or in the case of primary cells, transferring the cells into culture) can lead to differential expression of phenotype. Finally, cells in vitro have a limited ability to tolerate live bacterial challenge, and the strain of $P$. aeruginosa that is used in an experiment can influence the inflammatory response..$^{73}$ In vitro cell culture studies have been extremely useful in CF inflammation research and models are being improved to better recapitulate the human airway. However, it appears unlikely that these methods, in isolation, will be adequate to accurately predict the most promising drugs for clinical trials.

\section{Animal models}

The mouse, which has $78 \%$ sequence homology with humans, has been used extensively in CF research. ${ }^{81}$ Mice are relatively inexpensive, easy to produce and to manipulate genetically, and widely available compared with other CF animal models. However, there are differences in airway morphology between the mouse and human. ${ }^{82,83}$ More importantly, although many CF mouse models show exaggerated inflammatory response in the airway and certain mice demonstrate aspects of altered pulmonary physiology consistent with CF lung disease, none develops the full spectrum of chronically inflamed 
and infected airways.$^{84}$ Furthermore, the phenotype of each mutant mouse is dictated not only by the Cftr mutation, but also by the genetic background and environment of the animal, making proper controls essential in these studies. ${ }^{84}$ For many reasons, the CF mouse has been a useful in vivo mammalian model for inflammation research; however, present limitations must be considered when using these animals to determine clinical promise of new therapies.

Because of the limitations posed by the mouse model, researchers have investigated use of other animal models with the hope that lung function, size, and architecture would be more like that of humans. The sheep, ferret, and the pig, each having $>90 \%$ sequence homology with humans, are models under development. ${ }^{85-88}$ Early data from the CFTR -/- pig shows that the newborn piglets have nasal voltage measurements consistent with CFTR dysfunction and pancreatic exocrine insufficiency. ${ }^{89}$ Recent reports from 5 CF pigs surviving to several months of age indicates that they may develop a lung phenotype similar to that seen in humans. ${ }^{90}$ If survival for these animals can be improved and this model does consistently develop lung disease similar to that of humans, the model will be humans, it will be an invaluable resource for testing new drug therapies. Practical considerations of cost and broad availability to the research community will also need to be addressed in this process. Finally, it should be noted that thus far, survival of CF piglets has required intestinal surgery at birth performed by skilled investigators.

\section{Challenges for design of clinical trials when testing new therapies}

Until an adequate animal model of CF lung disease is developed, much of the efficacy and safety data must be generated in human subjects with $\mathrm{CF}$ for new therapies that show promise in current preclinical models. As an orphan disease with only approximately 30,000 patients in the United States and 70,000 worldwide, the number of patients available to participate in clinical trials is limited. ${ }^{91-93}$ Furthermore, because it is a progressive, multisystem disease, there is wide variability in disease burden between patients. Potential confounders that must be considered in trial design and analysis include but are not limited to pulmonary function, gender, bacterial infection, presence of CF-related diabetes, mutation class, pancreatic function, and nutritional status. ${ }^{74}$

Large, placebo-controlled, double-blinded, multicenter clinical trials are necessary to provide adequate data for Federal Drug Administration (FDA) approval. However, to demonstrate that these large trials are warranted, smaller trials that evaluate efficacy and safety of a candidate drug must be conducted first. One such trial design is the proof of concept. ${ }^{81}$ A successful proof of concept study provides positive outcome data that is specific to the biological process the drug is intended to effect. It should also provide preliminary data that reflects that the drug is safe. In addition, because pharmacokinetics often differ in patients with $\mathrm{CF}^{94-96}$ it is important to establish appropriate dosing prior to progressing to large trials of a new drug. In consideration of all these factors, design of proof of concept trials must include stringent inclusion and exclusion criteria, collection of outcome measures that support the biologic effects of the drug, and pharmacokinetic data that suggests the chosen dose is adequate for patients with CF. These requirements must be balanced so that the cost and burden to subjects will not prevent completion of the study. Study design of these initial trials is critical as CF studies, similar to those of many orphan diseases, can easily become underpowered to detect significant differences in the primary outcomes. This makes it difficult to justify larger, more costly studies and promising new therapies may be lost to future development.

One of the most significant challenges to testing new therapies in $\mathrm{CF}$ is determining appropriate outcome measures. Outcomes used in clinical trials for treatment with anti-inflammatory therapies have traditionally included clinical efficacy measures such as time to next exacerbation, or surrogate end points such as pulmonary function (usually $\mathrm{FEV}_{1}$ and/or rate of decline of $\left.\mathrm{FEV}_{1}\right) .{ }^{10,11,13,14,97,98} \mathrm{As}$ a result of improvements in clinical care, the rate of decline of lung function in patients with CF has slowed substantially. ${ }^{99}$ In addition, rates of exacerbation in patients with relatively less lung damage are lower than in those with more severe disease. ${ }^{100}$ However, it is these patients who may benefit most from anti-inflammatory treatment to prevent pulmonary decline over time. Thus, using lung function or pulmonary exacerbations as primary end points in clinical trials requires a large number of patients over a significant length of time to detect differences in these clinical parameters. ${ }^{101}$ The FDA is increasingly accepting and encouraging the use of measures designed to assess Patient Reported Outcomes (PROs) such as health-related quality of life (eg, the Cystic Fibrosis Questionnaire-Revised). ${ }^{102}$ However, this may be problematic when studying a chronic therapy aimed at reducing the rate of decline in health over a lifetime. As in the case of $\mathrm{FEV}_{1}$ and pulmonary exacerbations, either prohibitively long follow up or large numbers of subjects may be needed to detect a significant difference in PROs. ${ }^{74}$ 
Given the limited numbers of potential research subjects and the need to maximize limited resources, early phase studies must delicately balance the risk of underpowered results with the burden of subject participation and cost. For new anti-inflammatory therapies, other outcome measures may be more sensitive for detecting short-term response to treatment. In recognition of the need to develop and implement novel outcome measures for use in $\mathrm{CF}$ clinical research, the Cystic Fibrosis Foundation (CFF) Therapeutics Development Network (TDN) established outcome-measures working groups to make recommendations. ${ }^{103}$ Mayer-Hamblett et al ${ }^{103}$ also defined standards by which new outcome measures should be evaluated: a new outcome measure should be biologically relevant, sensitive and specific to treatment effects, reproducible, and feasible. The remainder of this portion of the review focuses on potential outcome measures for use in trials of new anti-inflammatory therapies.

\section{Systemic biomarkers}

Because a systemic biomarker of inflammation would be readily obtainable (in blood or urine) from a patient of any age and with any severity of pulmonary disease, researchers have evaluated such measures in patients with stable disease and in those experiencing exacerbations. ${ }^{104-119}$ Although, some systemic markers have shown response to systemic antibiotic therapy, ${ }^{104,110,112,115,120}$ there is concern that approach may not be sufficiently sensitive to detect changes that are occurring in the lung in response to a new anti-inflammatory therapy (Table 1). ${ }^{121}$

\section{Bronchoalveolar lavage}

The lung or, more precisely, the airway is the most active site of CF-related inflammation; thus, there has been substantial focus on developing biomarkers that are measurable in airway samples. Bronchoscopy with BAL is considered the gold standard for evaluation of lung inflammation, and has been used to evaluate response to therapy in many CF clinical trials. ${ }^{122-131}$ However, this procedure is invasive, resource intensive and samples only a small portion of the lung. ${ }^{121}$ Two less invasive means of capturing airway specimens are exhaled breath condensate (EBC) and sputum collection.

\section{Exhaled breath condensate}

EBC collection allows measurement of markers even in those CF patients who do not produce sputum. Markers of inflammation, NO, and $\mathrm{pH}$ have been studied in the EBC of adult and pediatric patients with $\mathrm{CF}{ }^{132-139}$ In some studies, $\mathrm{pH}$ and markers of inflammation in EBC from patients with $\mathrm{CF}$ who are experiencing an exacerbation have been shown to respond to antibiotic therapy. ${ }^{132,136,138}$ In response to the increasing interest in use of EBC to study pulmonary disease, the American Thoracic and European Respiratory Societies collaborated to make recommendations for optimal collection and analysis techniques. ${ }^{6}$ These efforts are promising, though concerns over sensitivity and specificity of this technique have been expressed. Many traditional inflammatory indices may not be volatile enough to accurately measure by this technique.

\section{Sputum biomarkers}

More extensive work has been done by CF researchers to evaluate the use of sputum biomarkers to sample lower airway secretions and response to therapy. Because patients with mild disease rarely produce sputum when stable, some studies have utilized sputum induction. For example, Ordonez et al ${ }^{140}$ studied pretherapy and posttherapy inflammatory markers in induced sputum following treatment with IV antibiotics.

Table I Current and potential outcome measures for use in clinical trials of new anti-inflammatory therapies in CF

\begin{tabular}{|c|c|c|}
\hline Outcome measure & Examples & Reference(s) \\
\hline Clinical efficacy & $\mathrm{FEV}_{1}$, rate of decline of $\mathrm{FEV}_{1}$, rate of exacerbations & $10,11,13,14,97,98$ \\
\hline Patient reported & CF-HQR & 102 \\
\hline \multicolumn{3}{|l|}{ outcome } \\
\hline \multirow[t]{2}{*}{ BAL markers } & Neutrophils, bacterial count, elastase IL-8, TNF- $\alpha$, & $|22-13|$ \\
\hline & soluable ICAM-I, LB4 & \\
\hline EBC markers & NO, pH, MMP-9 & $132-139$ \\
\hline \multirow[t]{2}{*}{ Sputum markers } & White cell count, bacterial count, elastase IL-6, & $140-143$ \\
\hline & IL-8, IL-I0, TNF- $\alpha$ & \\
\hline Systemic markers & CRP, NE-APC, TNF- $\alpha$, IL-I, IL-2, IL-8, EGF & $104-119$ \\
\hline CT scan & CT score, airway trapping, airway wall thickening & $145-152$ \\
\hline \multirow[t]{2}{*}{ MRI } & Structural changes, lung perfusion/pulmonary blood & $154-158$ \\
\hline & flow, ventilation defects & \\
\hline
\end{tabular}

Note: Table does not include exhaustive list of examples for each outcome measure. For comprehensive review of outcome measures in clinical trials for CF patients/ candidate biomarkers for CF airway inflammation. See references 74 and I2I.

Abbreviations: $\mathrm{FEV}_{1}$, forced expiratory volume in I second; IL, interleukin; TNF, tumor necrosis factor; L, leukotriene; NO, nitric oxide; MMP, matrix metalloprotein; CRP, C-reactive protein; NE-APC, neutrophil antiproteinase complex; EGF, endothelial growth factor; CT, computed tomography; MRI, magnetic resonance imaging; CF, cystic fibrosis. 
Total sputum white cell count, active elastase, IL-8, and $P$. aeruginosa counts were significantly decreased after antibiotic therapy. ${ }^{140}$ Although sputum induction was used in this study, expectorated sputum has also been shown to reflect airway inflammation in CF. ${ }^{141,142}$ Sagel et al ${ }^{143}$ demonstrated that in patients with $\mathrm{CF}$, measurement of inflammatory markers is comparable in induced and expectorated sputum. Thus, either method can be successfully employed in clinical trials in which sputum biomarkers will be an end point.

To assess the association between sputum biomarkers and clinical parameters, Mayer-Hamblett et $\mathrm{al}^{101}$ constructed a database of sputum biomarkers and pulmonary function data from 4 multicenter CF clinical trials to demonstrate the strength of association between expectorated sputum biomarkers and lung disease severity. Both elastase and IL-8 were negatively correlated with lung function in this diverse group of CF patients. Of the markers tested, sputum elastase showed the strongest correlation with $\mathrm{FEV}_{1}$ (correlation, $0.35 ; 95 \%$ confidence interval [CI], -046 to -0.22 ). On average, $\mathrm{CF}$ patients whose sputum elastase measurements differed by 0.5 logs differed in their $\mathrm{FEV}_{1}$ values by $-7.3 \%$ (95\% CI, -9.7 to -4.6 ). Finally, sputum elastase was shown to have a significant longitudinal association with $\mathrm{FEV}_{1}$ : a $-2.9 \%$ decline in $\mathrm{FEV}_{1}$ for every log increase in elastase. Thus, differences in sputum elastase correlated well with clinically meaningful differences in lung function, providing a useful biomarker, particularly for studies in which the intervention would likely preserve function through mechanisms that would also reduce the airway elastase concentration. ${ }^{101}$

Aware that differences in collection of sputum and analysis of biomarkers may lead to variability in results, and thus decrease the reproducibility of test results, the CFF TDN created standard operating procedures (SOPs) for both collection of sputum by induction and processing of sputum. ${ }^{121}$ In addition, core laboratories were established for analysis of sputum inflammatory biomarkers and sputum cytology (The Children's Hospital/University of Colorado Health Sciences Center and Case Western Reserve University, respectively.) Use of SOPs and core laboratories for centralized analysis will insure consistency of results from single and multicenter studies.

\section{Computed tomography (CT)}

Although induced sputum and EBC can be collected from children (as young as 10 years for induced sputum ${ }^{121}$ and 3-4 years for EBC, $)^{144}$ neither procedure is feasible in very young children and infants. Imaging such as CT and magnetic resonance imaging (MRI) would be applicable to subjects of all ages. Furthermore, therapies aimed at correcting the basic defects in $\mathrm{CF}$ are hoped to prevent or delay the onset of functional lung disease. Airway imaging would allow researchers to serially assess the presence and progression of structural lung damage.

Two separate longitudinal studies in patients with CF using every 2 or 3 year CT scans showed that scored CT images were more sensitive than spirometry for detecting disease progression. ${ }^{145,146}$ In addition, Brody et $\mathrm{al}^{147}$ showed that there was correlation between the frequency of pulmonary exacerbations and CT score. Small intervention studies in patients with CF have demonstrated improvement in overall CT score following treatment. ${ }^{148,149}$

In addition to evaluation of general structural changes, CT scan can be used to reproducibly measure airway wall thickness. Airway wall thickness can be reproducibly measured by CT scan. ${ }^{150-152}$ Because airway wall thickness is thought to correspond to airway inflammation, this measurement may be useful to monitor the efficacy of antiinflammatory therapies. Airway wall thickness has been successfully used to demonstrate response to inhaled steroids in asthmatic subjects. ${ }^{153}$ More data are needed to determine if this outcome measure will be useful in anti-inflammatory studies in CF lung disease. Investigators are faced with concerns over cumulative radiation exposure and potential need for sedation in the very young when designing these experiments.

\section{Magnetic resonance imaging}

Using proton-MRI sequences, structural changes such as bronchial wall thickening, mucus plugging, bronchiectasis, consolidation, and segmental destruction can be visualized. ${ }^{154}$ Although the spatial and temporal resolution of MRI of the lung is inferior to that of $\mathrm{CT}$, the lack of ionizing radiation makes MRI appealing as a repeated measure in clinical trials. Use of intravenous or inhaled contrast expands the potential of MRI in assessing CF lung disease. For example, with gadolinium-based intravenous contrast, MRI can examine lung perfusion and pulmonary blood flow. ${ }^{155,156}$ Inhaled hyperpolarized gas can provide a high MRI signal from airspaces of the lung. No ionizing radiation is used for these contrast studies and reported adverse events are mild. ${ }^{157}$ Using ventilation MRI imaging, Mentore et al ${ }^{158}$ demonstrated correlation between ventilation defects and spirometry. Furthermore, MRI imaging correlated with treatment and could detect abnormalities in subjects with normal spirometry. As in the case of sputum biomarkers, in order to use imaging techniques as outcome measures in clinical trials, SOPs will need to be created, and centralized reading centers where a common scoring system is used must be developed. ${ }^{159}$ 


\section{Future directions CFF pipeline-drug discovery program/CF therapeutics development network}

Through research funded by the CFF, both ibuprofen and azithromycin were shown to be beneficial in $\mathrm{CF}$ as described earlier. The CFF TDN is sponsoring a number of trials of potential new anti-inflammatory drugs, including both novel compounds and drugs that are FDA approved for other indications. ${ }^{160}$ Based on promising preclinical data, 3 FDAapproved drugs were recently tested in proof of concept trials including the immunosuppressant hydroxychoroquine, the HMG CoA reductase inhibitor, simvastatin and the PPAR gamma agonist, Pioglitazone. ${ }^{161-163}$ Although results of safety and efficacy of these 3 therapies were inconclusive, consideration is being given for longer trials. ${ }^{164}$

Another FDA-approved therapy, the phosphodiesterase inhibitor, sildenafil, is being studied through the CF TDN for its potential as an anti-inflammatory. Toward et al ${ }^{165}$ demonstrated that pretreatment with sildenafil inhibited LPS-induced airway hyperreactivity, white cell influx, and NO dysfunction in 2 guinea pig models of airway disease. ${ }^{165}$ In CF respiratory epithelial cells, Poschet et al ${ }^{166}$ showed that sildenafil exposure could reverse the excessive proinflammatory response to $P$ a aruginosa. In separate work, DBA/2 mice sensitive to $P$. aeruginosa were fed a diet with or without sildenafil. Following aerosol-delivered $P$. aeruginosa respiratory infection, myeloperoxidase in lung homogenates (a reflection of neutrophil infiltration) was reduced by $42 \% \pm 11 \%(P=0.047)$ in animals who received sildenafil-containing diets. ${ }^{167}$ Based on these data, sildenafil is currently being tested in a phase 2 trial.

A novel drug that is under investigation through the $\mathrm{CF}$ TDN is SB656933, a selective chemokine receptor (CXCR2) antagonist. This once-daily oral medication is also in a phase 2 multicenter study. The CFF is also funding investigation of drugs that may combat the pathogenic result of excessive inflammation by targeting antioxidant deficiencies. The ability of $\mathrm{N}$-acetylcysteine (an oral agent that replenishes glutathione levels) to modulate inflammation in CF was studied by Tirouvanziam et al. ${ }^{168}$ In this proof of concept study, CF patients were treated for 4 weeks, and inflammatory markers in expectorated sputum were assessed. In addition to increased glutathione levels in blood and in neutrophils, researchers found that sputum elastase was significantly decreased following treatment with $\mathrm{N}$-acetylcysteine. Based on these results, a multicenter phase $2 b$ is underway. Targeting similar mechanisms, a phase 2 trial of inhaled glutathione is being conducted in Germany. Finally, a multicenter study of DHA supplementation is also ongoing. As discussed earlier, DHA supports anti-inflammatory signaling that may be impaired in CF (eg, PPAR $\gamma$ ).

In summary, preclinical models of CF have provided invaluable information about the pathophysiology of CF lung disease, highlighting many molecular mechanisms which promote an exaggerated host inflammatory response. However, significant limitations of these models present challenges when trying to identify promising anti-inflammatory therapies for clinical trials. Similarly, inherent qualities of CF (eg, variable disease burden, relatively slow progression, limited number of potential subjects, etc) require thoughtful planning for early human studies to balance patient burden and cost with risk of underpowered data. Improving preclinical models of CF lung disease and developing useful and more dynamic surrogates of pulmonary function (ie, biomarkers) will help to overcome these challenges and significantly accelerate progress toward identifying new anti-inflammatory therapies. The $\mathrm{CF}$ research community continues to identify and test promising drugs, while many patients benefit from those already in use.

\section{Disclosure}

The authors report no conflicts of interest in this work.

\section{References}

1. Davis PB, Drumm M, Konstan MW. Cystic fibrosis: state of the art. Am J Respir Crit Care Med. 1996;154:1229-1256.

2. Bedrossian CW, Greenberg SD, Singer DB, et al. The lung in cystic fibrosis. A quantitative study including prevalence or pathologic findings among different age groups. Hum Pathol. 1976;7(2):195-204.

3. Khan TZ, Wagener JS, Bost T, et al. Early pulmonary inflammation in infants with cystic fibrosis. Am J Respir Crit Care Med. 1995;151:1075-1082.

4. Bonfield TL, Panuska JR, Konstan MW, et al. Inflammatory cytokines in cystic fibrosis lungs. Am J Respir Crit Care Med. 1995;152:2111-2118.

5. Konstan MW, Hilliard KA, Norvell TM, et al. Bronchoalveolar lavage findings in cystic fibrosis patients with stable, clinically mild lung disease suggest ongoing infection and inflammation. Am J Respir Crit Care Med. 1994;150:448-454.

6. Balough K, McCubbin M, Weinberger M, et al. The relationship between infection and inflammation in the early stages of lung disease from cystic fibrosis. Pediatr Pulmonol. 1995;20:63-70.

7. Armstrong DS, Grimwood K, Carlin JB, et al. Lower airway inflammation in infants and young children with cystic fibrosis. Am J Respir Crit Care Med. 1997;156:1197-1204

8. Muhlebach MS, Stewart PW, Leigh MW, et al. Quantitation of inflammatory response to bacteria in young cystic fibrosis and control patients. Am J Respir Crit Care Med. 1999;160:186-191.

9. Auerbach HS, Williams M, Kirkpatrick JA, et al. Alternate-day prednisone reduces morbidity and improves pulmonary function in cystic fibrosis. Lancet. 1985;2(8457):686-688.

10. Eigen H, Rosenstein BJ, FitzSimmons S, et al. A multicenter study of alternate-day prednisone therapy in patients with cystic fibrosis. Cystic Fibrosis Foundation Prednisone Trial Group. J Pediatr. 1995;126(4):515-523. 
11. Konstan MW, Byard PJ, Hoppel CL, et al. Effect of high-dose ibuprofen in patients with cystic fibrosis. N Engl J Med. 1995;332:848-844.

12. Donati MA, Haver K, Gerson W, et al. Long-term alternate day prednisone therapy in cystic fibrosis. Pediatr Pulmonol. 1990;5:A322.

13. Lands LC, Milner R, Cantin AM, et al. High-dose ibuprofen in cystic fibrosis: Canadian safety and effectiveness trial. $J$ Pediatr. 2007;151:228-230.

14. Konstan MW, Schluchter MD, Xue W, et al. Clinical use of ibuprofen is associated with slower FEV1 decline in children with cystic fibrosis Am J Respir Crit Care Med. 2007;176:1084-1089.

15. Noah TL, Black HR, Cheng PW, et al. Nasal and bronchoalveolar lavage fluid cytokines in early cystic fibrosis. J Infect Dis. 1997; 175:638-647.

16. Perez A, Issler AC, Cotton CU, et al. CFTR inhibition mimics the cystic fibrosis inflammatory profile. Am J Physiol Lung Cell Mol Physiol. 2007;292:L383-L395.

17. Dechecchi MC, Nicolis E, Bezzerri V, et al. MPB-07 reduces the inflammatory response to Pseudomonas aeruginosa in cystic fibrosis bronchial cells. Am J Respir Cell Mol Biol. 2007;36: 615-624.

18. van Heeckeren A, Walenga R, Konstan MW, et al. Excessive inflammatory response on cystic fibrosis mice to bronchopulmonary infection with P. aeruginosa. J Clin Invest. 1997;100:2810-2815.

19. McMorran BJ, Palmer JS, Lunn DP, et al. G551D CF mice display an abnormal host response and have impaired clearance of Pseudomonas lung disease. Am J Physiol Lung Cel Mol Physiol. 2001;281:L740-L747.

20. Verhaeghe C, Remouchamps C, Hennuy B, et al. Role of IKK and ERK pathways in intrinsic inflammation of cystic fibrosis airways. Biochem Pharmacol. 2007;73:1982-1994.

21. Li J, Johnson XD, Lazvovskaia S, et al. Signaling intermediates required for NFKB activation and IL-8 expression in CF bronchial epithelial cells. Am J Physiol Lung Cell Mol Physiol. 2003;284:L307-L315.

22. Escotte S, Tabary O, Dusser D, et al. Fluticasone reduces IL-6 and IL- 8 production of cystic fibrosis bronchial epithelial cells via IKK-beta kinase pathway. Eur Respir J. 2003;21:574-581.

23. Ribeiro CM, Paradiso AM, Schwab U, et al. Chronic airway infection/inflammation induces a $\mathrm{Ca} 2+\mathrm{i}$-dependent hyperinflammatory response in human cystic fibrosis airway epithelia. $J$ Biol Chem 2005;280:17798-17806.

24. Bonfield TL, Konstan MW, Burfeind P, et al. Normal bronchial epithelial cells constitutively produce the anti-inflammatory cytokine interleukin-10, which is downregulated in cystic fibrosis. Am J Respir Cell Mol Biol. 1995;13:257-261.

25. Bonfield TL, Konstan MW, Berger M. Altered respiratory epithelial cell cytokine production in cystic fibrosis. J Allergy Clin Immunol. 1999;104(1):72-78.

26. Moore KW, de Waal-Malefyt R, Coffman RL, et al. Interleukin-10 and the interleukin-10 receptor. Annu Rev Immunol. 2001;19:683-765.

27. Osika E, Cavaillon JM, Chadelat K, et al. Distinct sputum cytokine profiles in cystic fibrosis and other chronic inflammatory airway disease. Eur Respir J. 1999;14:339-346.

28. Lentsch AB, Shanley TP, Sarma V, et al. In vivo suppression of NFkB and preservation of IkBalpha by interleukin-10 and interleukin-13. J Clin Invest. 1997;100:2443-2448.

29. Schottelius AJG, Mayo MW, Sartor RB, et al. Interleukin-10 signaling blocks inhibitor of $\mathrm{kB}$ kinase activity and nuclear factor $\mathrm{kB}$ DNA binding. J Biol Chem. 1999;274:31868-31874.

30. Andersson C, Zaman MM, Jones AB, et al. Alterations in immune respnse and PPAR/LXR regulation in cystic fibrosis macrophages. J Cyst Fibros. 2008;7(1):68-78.

31. Ollero M, Junaidi O, Zaman MM, et al. Decreased expression of peroxisome proliferator activated receptor gamma in cftr-/- mice. $J$ Cell Physiol. 2004;200:235-244.

32. Karp CL, Flick LM, Park KW, et al. Defective lipoxin-mediated antiinflammatory activity in the cystic fibrosis airway. Nat Immunol. 2004;5:357-358.
33. Starosta V, Ratjen F, Rietschel E, et al. Anti-inflammatory cytokines in cystic fibrosis lung disease. Eur Respir J. 2006;28:581-587.

34. Dubin PJ, McAllister F, Kolls JK. Is cystic fibrosis a TH17 disease? Inflamm Res. 2007;56:221-227.

35. Dubin PJ, Kolls JK. IL-23 mediates inflammatory responses to mucoid pseudomonas aeruginosa lung infection in mice. Am J Physiol Lung Cel Mol Physiol. 2007;292:L519-L523.

36. McAllister F, Henry A, Kreindler JL, et al. Role of IL-17A, IL-17F, and the IL-17 receptor in regulating growth related oncogene-alpha and granulocyte colony-stimulating factor in bronchial epithelium: implications for airway inflammation in cystic fibrosis. J Immunol. 2005; 175:404-412.

37. Roussel L, Rousseau S. IL-17 primes airway epithelial cells lacking functional CFTR in increase NOD1 responses. Biochem Biophys Res Commun. 2010;391(1):505-509.

38. Fujisawa T, Velichko S, Thai $\mathrm{P}$, et al. Regulation of airway MUC5AC expression by IL-1beta and IL-17A; the NF-kappaB paradigm. J Immunol. 2009;183(10):6236-6243.

39. Ferretti S, Bonneau O, Dubois GR, et al. IL-17, produced by lymphocytes and neutrophils, is necessary for lipopolysaccharide induced airway neutrophilia: IL-15 as a possible trigger. J Immunol. 2003;170:2106-2112.

40. Chen J, Kinter M, Shank S, et al. Dysfunction of Nrf-2 in CF epithelia leads to excess intracellular $\mathrm{H}_{2} \mathrm{O}_{2}$ and inflammatory cytokine production. PLOS ONE. 2008;3:e3367.

41. Li Q, Engelhardt JF. Interleukin-1B induction of NFkB is partially regulated by $\mathrm{H}_{2} \mathrm{O}_{2}$-mediated activation of NFkB-inducing kinase. $J$ Biol Chem. 2006;281:1495-1505.

42. Balfour-Lynn IM, Laverty A, Dinwiddie R. Reduced upper airway nitric oxide in cystic fibrosis. Arch Dis Child. 1996;75:319-322.

43. Grasemann H, Michler E, Wallot M, et al. Decreased concentration of exhaled nitric oxide (NO) in patients with cystic fibrosis. Pediatr Pulmonol. 1997;24:173-177.

44. Roum JH, Buhl R, McElvaney NG, et al. Systemic deficiency of glutathione in cystic fibrosis. J Appl Physiol. 1993;75:2419-2424.

45. Gao L, Kim KJ, Yankaskas JR, et al. Abnormal glutathione transport in cystic fibrosis airway epithelia. Am J Physiol. 1999;277:L113-L118.

46. Nichols DP, Ziady AG, Shank SL, et al. The triterpenoid CDDO limits inflammation in preclinical models of cystic fibrosis lung disease. $\mathrm{Am}$ J Physiol Lung Cel Mol Physiol. 2009;297(5):L828-L836.

47. Ishii Y, Itoh K, Morishima Y, et al. Transcription factor Nrf2 plays a pivotal role in protection against elastase-induced pulmonary inflammation and emphysema. J Immunol. 2005;175:6968-6975.

48. Gaggar A, Jackson PL, Noerager BD, et al. A novel proteolytic cascade generates an extracellular matrix-derived chemoattractant in chronic neutrophilic inflammation. J Immunol. 2008;180:5662-5669.

49. Jackson PL, Xu X, Wilson L, et al. Human neutrophil elastase-mediated cleavage sites on MMP-9 and TIMP-1: implications to cystic fibrosis proteolytic dysfunction. Mol Med. 2010. Epub 2010 Jan 29.

50. Weldon S, McNally P, McElvaney NG, et al. Decreased levels of secretory leucoprotease inhibitor in the pseudomonas-infected cystic fibrosis lung are due to neutrophil elastase degredation. J Immunol. 2009; 183:8146-8156.

51. Goyot N, Butler MW, McNally P, et al. Elafin, an elastase-specific inhibitor, is cleaved by its cognate enzyme neutrophil elastase in sputum from individuals with cystic fibrosis. $J$ Biol Chem. 2008;283(47):32377-32385.

52. Oermann CM, Sockrider MM, Konstan MW. The use of anti-inflammatory medications in cystic fibrosis: trends, and physician attitudes. Chest. 1999;115:1053-1058.

53. Matthews WJ, Williams M, Oliphint B, et al. Hypogammaglobulinemia in patients with cystic fibrosis. N Engl J Med. 1980;302:245-249.

54. Eigen H, Rosenstein BJ, FitzSimmons S, et al. A multicenter study of alternate-day prednisone therapy in patients with cystic fibrosis. J Pediatr. 1995;126(4):515-523.

55. Rosenstein BJ, Eigen H. Risks of alternate day prednisone in patients with cystic fibrosis. Pediatr. 1991;87:245-246. 
56. Lai HC, FitzSimmons SC, Allen DB. Risk of persistent growth impairment after alternate-day prednisone treatment in children with cystic fibrosis. N Engl J Med. 2000;342:851-859.

57. Greally P, Hussain MJ, Vergani D, et al. Interleukin-1alpha, soluble interleukin-2 receptor, and IgG concentrations in cystic fibrosis treated with prednisolone. Arch Dis Child. 1994;71:35-39.

58. Balfour-Lynn IM, Welch K. Inhaled corticosteroids for cystic fibrosis. Cochrane Database Syst Rev. 2009;1.

59. Konstan MW, Vargo KM, Davis PB. Ibuprofen attenuates the inflammatory response to Pseudomonas aeruginosa in a rat model of chroic pulmonary infection. Am Rev Respir Dis. 1990;141:186-192.

60. Scheuren N, Bang H, Munster T, et al. Modulation of transcription factor NF-kappaB by enantiomers of the nonsteroidal drug ibuprofen. Br J Pharmacol. 1998;123:645-652.

61. Tegeder I, Niederberger E, Israr E, et al. Inhibition of NF-kB and AP-1 activation by R- and S-flurbiprofen. FASEB J. 2001;15:595-597.

62. Saiman L, Marshall BC, Mayer-Hamblett N, et al. Azithromycin in patients with cystic fibrosis chronically infected with Pseudomonas aeruginosa: a randomized controlled trial. JAMA. 2003;290:1749-1756.

63. Florescu DF, Murphy PJ, Kalil AC. Effects of prolonged use of azithromycin in patients with cystic fibrosis: a meta-analysis. Pulm Pharmacol Ther. 2009;22(6):467-472.

64. Equi A, Balfour-Lynn IM, Bush A, et al. Long term azithromycin in children with cystic fibrosis: a randomised, placebo-controlled crossover trial. Lancet. 2002;360:978-984.

65. Verleden GM, Vanaudenaerde BM, Dupont LJ, et al. Azithromycin reduces airway neutrophilia and interleukin-8 in patients with bronchiolitis obliterans syndrome. Am J Respir Crit Care Med. 2006;174:566-570.

66. Tsai WC, Rodriguez ML, Young KS, et al. Azithromycin blocks neutrophil recruitment in pseudomonas endobronchial infection. Am J Respir Crit Care Med. 2004;170:1331-1339.

67. Culic O, Erakovic V, Cepelak I, et al. Azithromycin modulates neutrophil function and circulating inflammatory mediators in healthy human subjects. Eur J Pharmacol. 2002;450:277-289.

68. Hoffmann N, Lee B, Hentzer M, et al. Azithromycin blocks quorum sensing and alginate polymer formation an dincreases the sensitivity to serum and stationary-growth-phase killing of pseudomonas aeruginosa and attenuates chronic P. aeruginosa lung infection in $\mathrm{cftr}(-/-)$ mice. Antimicrob Agents Chemother. 2007;51:3677-3687.

69. Gavilanes X, Huaux F, Meyer M, et al. Azithromycin fails to reduce increased expression of neutrophil-related cytokines in primarycultured epithelial cells from cystic fibrosis mice. J Cyst Fibros. 2009;8(3):203-210.

70. Ribeiro $\mathrm{CM}$, Hurd $\mathrm{H}, \mathrm{Wu} \mathrm{Y}$, et al. Azithromycin treatment alters gene expression in inflammatory, lipid metabolism, and cell cycle pathways in well-differentiated human airway epithelia. PLOS ONE. 2009;4(6):e5806.

71. Tramper-Stranders GA, Wolfs TF, Fleer A, et al. Maintenance azithromycin treatment in pediatric patients with cystic fibrosis: long-term outcomes related to macrolide resistance and pulmonary function. Pediatr Infect Dis J. 2007;26:8-12.

72. Saiman L, Anstead M, Mayer-Hamblett N, et al. Effect of azithromycin on pulmonary function in patients with cystic fibrosis uninfected with Pseudomonas aeruginosa: a randomized controlled trial. JAMA. 2010;303:1707-1715.

73. Gruenert DC, Willems M, Cassiman JJ, et al. Established cell lines used in cystic fibrosis research. J Cyst Fibros. 2004;3 Suppl 2:191-196.

74. Doring G, Elborn JS, Johannesson M, et al. Clinical trials in cystic fibrosis. J Cyst Fibros. 2007;6(2):85-99.

75. DiMango E, Ratner AJ, Bryan R, et al. Activation of NF-kappaB by adherent Pseudomonas aeruginosa in normal and cystic fibrosis respiratory epithelial cells. J Clin Invest. 1998;101(11):2598-2605.

76. Kube D, Sontich U, Fletcher D, et al. Proinflammatory cytokine responses to P. aeruginosa infection in human airway epithelial cell lines. Am J Physiol Lung Cell Mol Physiol. 2001;280(3):L493-L502.
77. Kammouni W, Figarella C, Marchand S, et al. Altered cytokine production by cystic fibrosis tracheal gland serous cells. Infect Immun. 1997;65(12):5176-5183.

78. Weber AJ, Soong G, Bryan R, et al. Activation of NF-kappaB in airway epithelial cells is dependent on CFTR trafficking and Clchannel function. Am J Physiol Lung Cell Mol Physiol. 2001;281(1): L71-L78.

79. Borgatti M, Bezzerri V, Mancini I, et al. Induction of IL-6 gene expression in a CF bronchial epithelial cell line by Pseudomonas aeruginosa is dependent on transcription factors belonging to the Sp1 superfamily. Biochem Biophys Res Commun. 2007;357(4): 977-983.

80. Li J, Johnson XD, Iazvovskaia S, et al. Signaling intermediates required for NF-kappa B activation and IL-8 expression in CF bronchial epithelial cells. Am J Physiol Lung Cell Mol Physiol. 2003;284(2):L307-L315.

81. Banner KH, De Jonge H, Elborn S, et al. Highlights of a workshop to discuss targeting inflammation in cystic fibrosis. $J$ Cyst Fibros. 2009;8(1):1-8.

82. Borthwick DW, West JD, Keighren MA, et al. Murine submucosal glands are clonally derived and show a cystic fibrosis gene-dependent distribution pattern. Am J Respir Cell Mol Biol. 1999;20(6):1181-1189.

83. Pack RJ, Al-Ugaily LH, Morris G, et al. The distribution and structure of cells in the tracheal epithelium of the mouse. Cell Tissue Res. 1980;208(1):65-84.

84. Scholte BJ, Davidson DJ, Wilke M, et al. Animal models of cystic fibrosis. J Cyst Fibros. 2004;3 Suppl 2:183-190.

85. Harris A. Towards an ovine model of cystic fibrosis. Hum Mol Genet. 1997;6(13):2191-2194.

86. Sun X, Yan Z, YiY, et al. Adeno-associated virus-targeted disruption of the CFTR gene in cloned ferrets. J Clin Invest. 2008;118(4):1578-1583.

87. Rogers CS, Stoltz DA, Meyerholz DK, et al. Disruption of the CFTR gene produces a model of cystic fibrosis in newborn pigs. Science. 26 2008;321(5897):1837-1841.

88. Rogers CS, Hao Y, Rokhlina T, et al. Production of CFTR-null and CFTR-DeltaF508 heterozygous pigs by adeno-associated virus-mediated gene targeting and somatic cell nuclear transfer. J Clin Invest. 2008;118(4):1571-1577.

89. Stoltz DA. Early Pulmonary Findings in a CFTR -/- Pig. North American Cystic Fibrosis Conference. Minneapolis, MN: Wiley-Blackwell; 2009:191.

90. Stoltz DA, Meyerholz DK, Pezzulo AA, et al. Cystic fibrosis pigs develop lung disease and exhibit defective bacterial eradication at birth. Sci Transl Med. 2010;2:29ra31.

91. Fibrosis FC. Cystic Fibrosis Foundation National Patient Registry, Annual Data Report, Bethesda, MD; 2007.

92. Farrell PM. The prevalence of cystic fibrosis in the European Union. $J$ Cyst Fibros. 2008;7(5):450-453.

93. McCormick J, Mehta G, Olesen HV, et al. Comparative demographics of the European cystic fibrosis population: a cross-sectional database analysis. Lancet. 20 2010;375(9719):1007-1013.

94. Parker AC, Pritchard P, Preston T, et al. Enhanced drug metabolism in young children with cystic fibrosis. Arch Dis Child. 1997;77(3):239-241.

95. Prandota J. Clinical pharmacology of antibiotics and other drugs in cystic fibrosis. Drugs. 1988;35(5):542-578.

96. Kearns GL. Hepatic drug metabolism in cystic fibrosis: recent developments and future directions. Ann Pharmacother. 1993;27(1):74-79.

97. Equi A, Balfour-Lynn IM, Bush A, et al. Long term azithromycin in children with cystic fibrosis: a randomised, placebo-controlled crossover trial. Lancet. 28 2002;360(9338):978-984.

98. Wolter J, Seeney S, Bell S, et al. Effect of long term treatment with azithromycin on disease parameters in cystic fibrosis: a randomised trial. Thorax. 2002;57(3):212-216.

99. McPhail GL, Acton JD, Fenchel MC, et al. Improvements in lung function outcomes in children with cystic fibrosis are associated with better nutrition, fewer chronic pseudomonas aeruginosa infections, and dornase alfa use. J Pediatr. 2008;153(6):752-757. 
100. Rabin HR, Butler SM, Wohl ME, et al. Pulmonary exacerbations in cystic fibrosis. Pediatr Pulmonol. 2004;37(5):400-406.

101. Mayer-Hamblett N, Aitken ML, Accurso FJ, et al. Association between pulmonary function and sputum biomarkers in cystic fibrosis. $A m J$ Respir Crit Care Med. 2007;175(8):822-828.

102. Quittner AL, Buu A, Messer MA, et al. Development and validation of The Cystic Fibrosis Questionnaire in the United States: a health-related quality-of-life measure for cystic fibrosis. Chest. 2005;128(4):2347-2354.

103. Mayer-Hamblett N, Ramsey BW, Kronmal RA. Advancing outcome measures for the new era of drug development in cystic fibrosis. Proc Am Thorac Soc. 2007;4(4):370-377.

104. Hendry J, Elborn JS, Nixon L, et al. Cystic fibrosis: inflammatory response to infection with Burkholderia cepacia and Pseudomonas aeruginosa. Eur Respir J. 1999;14(2):435-438.

105. Koller DY, Gotz M, Wojnarowski C, et al. Relationship between disease severity and inflammatory markers in cystic fibrosis. Arch Dis Child. 1996;75(6):498-501.

106. Norman D, Elborn JS, Cordon SM, et al. Plasma tumour necrosis factor alpha in cystic fibrosis. Thorax. 1991;46(2):91-95.

107. Brown MA, Morgan WJ, Finley PR, et al. Circulating levels of tumor necrosis factor and interleukin-1 in cystic fibrosis. Pediatr Pulmonol. 1991;10(2):86-91.

108. Dorlochter L, Carlsson M, Olafsdottir EJ, et al. Anti-neutrophil cytoplasmatic antibodies and lung disease in cystic fibrosis. J Cyst Fibros. 2004;3(3):179-183

109. Colombo C, Costantini D, Rocchi A, et al. Cytokine levels in sputum of cystic fibrosis patients before and after antibiotic therapy. Pediatr Pulmonol. 2005;40(1):15-21.

110. Roderfeld M, Rath T, Schulz R, et al. Serum matrix metalloproteinases in adult CF patients: relation to pulmonary exacerbation. J Cyst Fibros. 2009;8(5):338-347.

111. Jones AM, Martin L, Bright-Thomas RJ, et al. Inflammatory markers in cystic fibrosis patients with transmissible Pseudomonas aeruginosa. Eur Respir J. 2003;22(3):503-506.

112. Valletta EA, Rigo A, Bonazzi L, et al. Modification of some markers of inflammation during treatment for acute respiratory exacerbation in cystic fibrosis. Acta Paediatr. 1992;81(3): 227-230.

113. Downey DG, Martin SL, Dempster M, et al. The relationship of clinical and inflammatory markers to outcome in stable patients with cystic fibrosis. Pediatr Pulmonol. 2007;42(3):216-220.

114. Wilmott RW, Frenzke M, Kociela V, et al. Plasma interleukin-1 alpha and beta, tumor necrosis factor-alpha, and lipopolysaccharide concentrations during pulmonary exacerbations of cystic fibrosis Pediatr Pulmonol. 1994;18(1):21-27.

115. McColley SA, Stellmach V, Boas SR, et al. Serum vascular endothelial growth factor is elevated in cystic fibrosis and decreases with treatment of acute pulmonary exacerbation. Am J Respir Crit Care Med. 2000;161(6):1877-1880

116. Dean TP, Dai Y, Shute JK, et al. Interleukin-8 concentrations are elevated in bronchoalveolar lavage, sputum, and sera of children with cystic fibrosis. Pediatr Res. 1993;34(2):159-161.

117. Greally P, Hussain MJ, Vergani D, et al. Serum interleukin- 1 alpha and soluble interleukin-2 receptor concentrations in cystic fibrosis. Arch Dis Child. 1993;68(6):785-787.

118. Kronborg G, Hansen MB, Svenson M, et al. Cytokines in sputum and serum from patients with cystic fibrosis and chronic Pseudomonas aeruginosa infection as markers of destructive inflammation in the lungs. Pediatr Pulmonol. 1993;15(5):292-297.

119. Eichler I, Nilsson M, Rath R, et al. Human neutrophil lipocalin, a highly specific marker for acute exacerbation in cystic fibrosis. Eur Respir J. 1999;14(5):1145-1149.

120. Downey DG, Brockbank S, Martin SL, et al. Broncoscopy Study Group The effect of treatment of cystic fibrosis pulmonary exacerbations on airways and systemic inflammation. Pediatr Pulmonol. 2007;42(8):729-735.
121. Sagel SD, Chmiel JF, Konstan MW. Sputum biomarkers of inflammation in cystic fibrosis lung disease. Proc Am Thorac Soc. 2007;4(4):406-417.

122. Wagener JS, Rock MJ, McCubbin MM, et al. Aerosol delivery and safety of recombinant human deoxyribonuclease in young children with cystic fibrosis: a bronchoscopic study. Pulmozyme Pediatric. J Pediatr. 1998;133(4):486-491.

123. Wojtczak HA, Kerby GS, Wagener JS, et al. Beclomethasone diproprionate reduced airway inflammation without adrenal suppression in young children with cystic fibrosis: a pilot study. Pediatr Pulmonol. 2001;32(4):293-302.

124. Douglas TA, Brennan S, Gard S, et al. Acquisition and eradication of P. aeruginosa in young children with cystic fibrosis. Eur Respir J. 2009;33(2):305-311.

125. Gibson RL, Emerson J, Mayer-Hamblett N, et al. Duration of treatment effect after tobramycin solution for inhalation in young children with cystic fibrosis. Pediatr Pulmonol. 2007;42(7):610-623.

126. Ratjen F, Paul K, van Koningsbruggen S, et al. DNA concentrations in BAL fluid of cystic fibrosis patients with early lung disease: influence of treatment with dornase alpha. Pediatr Pulmonol. 2005;39(1): $1-4$.

127. Paul K, Rietschel E, Ballmann M, et al. Effect of treatment with dornase alpha on airway inflammation in patients with cystic fibrosis. Am J Respir Crit Care Med. 2004;169(6):719-725.

128. Ratjen F, Hartog CM, Paul K, et al. Matrix metalloproteases in BAL fluid of patients with cystic fibrosis and their modulation by treatment with dornase alpha. Thorax. 2002;57(11):930-934.

129. Meyer KC, Lewandoski JR, Zimmerman JJ, et al. Human neutrophil elastase and elastase/alpha 1-antiprotease complex in cystic fibrosis. Comparison with interstitial lung disease and evaluation of the effect of intravenously administered antibiotic therapy. Am Rev Respir Dis 1991;144(3 Pt 1):580-585.

130. McElvaney NG, Hubbard RC, Birrer P, et al. Aerosol alpha 1-antitrypsin treatment for cystic fibrosis. Lancet. 1991;337(8738):392-394.

131. McElvaney NG, Nakamura H, Birrer P, et al. Modulation of airway inflammation in cystic fibrosis. In vivo suppression of interleukin-8 levels on the respiratory epithelial surface by aerosolization of recombinant secretory leukoprotease inhibitor. $J$ Clin Invest. 1992;90(4):1296-1301.

132. Carpagnano GE, Barnes PJ, Francis J, et al. Breath condensate $\mathrm{pH}$ in children with cystic fibrosis and asthma: a new noninvasive marker of airway inflammation? Chest. 2004;125(6):2005-2010.

133. Karakoc GB, Inal A, Yilmaz M, et al. Exhaled breath condensate MMP-9 levels in children with bronchiectasis. Pediatr Pulmonol. 2009;44(10):1010-1016.

134. Robroeks CM, Rosias PP, van Vliet D, et al. Biomarkers in exhaled breath condensate indicate presence and severity of cystic fibrosis in children. Pediatr Allergy Immunol. 2008;19(7):652-659.

135. Thomas SR, Kharitonov SA, Scott SF, et al. Nasal and exhaled nitric oxide is reduced in adult patients with cystic fibrosis and does not correlate with cystic fibrosis genotype. Chest. 2000;117(4):1085-1089.

136. Bodini A, D'Orazio C, Peroni D, et al. Biomarkers of neutrophilic inflammation in exhaled air of cystic fibrosis children with bacterial airway infections. Pediatr Pulmonol. 2005;40(6):494-499.

137. Ojoo JC, Mulrennan SA, Kastelik JA, et al. Exhaled breath condensate $\mathrm{pH}$ and exhaled nitric oxide in allergic asthma and in cystic fibrosis. Thorax. 2005;60(1):22-26.

138. Tate S, MacGregor G, Davis M, et al. Airways in cystic fibrosis are acidified: detection by exhaled breath condensate. Thorax. 2002;57(11):926-929.

139. Newport S, Amin N, Dozor AJ. Exhaled breath condensate $\mathrm{pH}$ and ammonia in cystic fibrosis and response to treatment of acute pulmonary exacerbations. Pediatr Pulmonol. 2009;44(9):866-872.

140. Ordonez CL, Henig NR, Mayer-Hamblett N, et al. Inflammatory and microbiologic markers in induced sputum after intravenous antibiotics in cystic fibrosis. Am J Respir Crit Care Med. 15, 2003;168(12):1471-1475. 
141. Gilljam H, Malmborg AS, Strandvik B. Conformity of bacterial growth in sputum and contamination free endobronchial samples in patients with cystic fibrosis. Thorax. 1986;41(8):641-646.

142. Aaron SD, Kottachchi D, Ferris WJ, et al. Sputum versus bronchoscopy for diagnosis of Pseudomonas aeruginosa biofilms in cystic fibrosis. Eur Respir J. 2004;24(4):631-637.

143. Sagel SD, Kapsner R, Osberg I, et al. Airway inflammation in children with cystic fibrosis and healthy children assessed by sputum induction. Am J Respir Crit Care Med. 15 2001;164(8 Pt 1):1425-1431.

144. Baraldi E, Ghiro L, Piovan V, et al. Safety and success of exhaled breath condensate collection in asthma. Arch Dis Child. 2003;88(4):358-360.

145. de Jong PA, Lindblad A, Rubin L, et al. Progression of lung disease on computed tomography and pulmonary function tests in children and adults with cystic fibrosis. Thorax. 2006;61(1):80-85.

146. de Jong PA, Nakano Y, Lequin MH, et al. Progressive damage on high resolution computed tomography despite stable lung function in cystic fibrosis. Eur Respir J. 2004;23(1):93-97.

147. Brody AS, Sucharew H, Campbell JD, et al. Computed tomography correlates with pulmonary exacerbations in children with cystic fibrosis. Am J Respir Crit Care Med. 2005;172(9):1128-1132.

148. Nasr SZ, Kuhns LR, Brown RW, et al. Use of computerized tomography and chest $\mathrm{x}$-rays in evaluating efficacy of aerosolized recombinant human DNase in cystic fibrosis patients younger than age 5 years: a preliminary study. Pediatr Pulmonol. 2001;31(5):377-382.

149. Robinson TE, Goris ML, Zhu HJ, et al. Dornase alfa reduces air trapping in children with mild cystic fibrosis lung disease: a quantitative analysis. Chest. 2005;128(4):2327-2335.

150. Nakano Y, Wong JC, de Jong PA, et al. The prediction of small airway dimensions using computed tomography. Am J Respir Crit Care Med. 2005;171(2):142-146.

151. Orlandi I, Moroni C, Camiciottoli G, et al. Chronic obstructive pulmonary disease: thin-section CT measurement of airway wall thickness and lung attenuation. Radiology. 2005;234(2):604-610.

152. de Jong PA, Nakano Y, Hop WC, et al. Changes in airway dimensions on computed tomography scans of children with cystic fibrosis. Am J Respir Crit Care Med. 2005;172(2):218-224.

153. Niimi A, Matsumoto H, Amitani R, et al. Effect of short-term treatment with inhaled corticosteroid on airway wall thickening in asthma. Am J Med. 2004;116(11):725-731.

154. Puderbach M, Eichinger M, Gahr J, et al. Proton MRI appearance of cystic fibrosis: comparison to CT. Eur Radiol. 2007;17(3): 716-724.
155. Eichinger M, Puderbach M, Fink C, et al. Contrast-enhanced 3D MRI of lung perfusion in children with cystic fibrosis - initial results. Eur Radiol. 2006;16(10):2147-2152.

156. Ley S, Puderbach M, Fink C, et al. Assessment of hemodynamic changes in the systemic and pulmonary arterial circulation in patients with cystic fibrosis using phase-contrast MRI. Eur Radiol. 2005;15(8):1575-1580.

157. Altes TA, Eichinger M, Puderbach M. Magnetic resonance imaging of the lung in cystic fibrosis. Proc Am Thorac Soc. 2007;4(4):321-327.

158. Mentore K, Froh DK, de Lange EE, et al. Hyperpolarized HHe 3 MRI of the lung in cystic fibrosis: assessment at baseline and after bronchodilator and airway clearance treatment. Acad Radiol. 2005;12(11):1423-1429.

159. Ramsey BW. Use of lung imaging studies as outcome measures for development of new therapies in cystic fibrosis. Proc Am Thorac Soc. 2007;4(4):359-363.

160. Foundation CF. CFF Drug Development Pipeline. Available from: http://www.cff.org/treatments/Pipeline/. Accessed Apr 5, 2010.

161. Williams B, Robinette M, Slovis B, Deretic V, Perkett E. Hydroxychoroquine: pilot study of anti-inflammatory effects in cystic fibrosis. Pediatr Pulmonol. 2008;(31):A314.

162. Kraynack NC, CJ, Xue W, et al. Effect of simvastatin on exhaled nitric oxide and inflammatory markers in sputum in patients with cystic fibrosis. Pediatr Pulmonol. 2008;(31):A300.

163. Konstan MW, HKA, Bucur C, et al. Effect of pioglitazone on sputum markers of inflammation in cystic fibrosis. Pediatr Pulmonol. 2008;(31):A310.

164. Ashlock MA, Beall RJ, Hamblett NM, et al. A pipeline of therapies for cystic fibrosis. Semin Respir Crit Care Med. 2009;30(5):611-626.

165. Toward TJ, Smith N, Broadley KJ. Effect of phosphodiesterase-5 inhibitor, sildenafil (Viagra), in animal models of airways disease. Am J Respir Crit Care Med. 2004;169(2):227-234.

166. Poschet JF, Fazio JA, Timmins GS, et al. Endosomal hyperacidification in cystic fibrosis is due to defective nitric oxide-cylic GMP signalling cascade. EMBO Rep. 2006;7(5):553-559.

167. Poschet JF, Timmins GS, Taylor-Cousar JL, et al. Pharmacological modulation of cGMP levels by phosphodiesterase 5 inhibitors as a therapeutic strategy for treatment of respiratory pathology in cystic fibrosis. Am J Physiol Lung Cell Mol Physiol. 2007;293(3):L712-L719.

168. Tirouvanziam R, Conrad CK, Bottiglieri T, et al. High-dose oral $\mathrm{N}$-acetylcysteine, a glutathione prodrug, modulates inflammation in cystic fibrosis. Proc Natl Acad Sci U S A. 2006;103(12):4628-4633.
Journal of Inflammation Research

\section{Publish your work in this journal}

The Journal of Inflammation Research is an international, peer-reviewed open-access journal that welcomes laboratory and clinical findings on the molecular basis, cell biology and pharmacology of inflammation including original research, reviews, symposium reports, hypothesis formation and commentaries on: acute/chronic inflammation; mediators of inflamma-

\section{Dovepress}

tion; cellular processes; molecular mechanisms; pharmacology and novel anti-inflammatory drugs; clinical conditions involving inflammation. The manuscript management system is completely online and includes a very quick and fair peer-review system. Visit http://www.dovepress.com/ testimonials.php to read real quotes from published authors. 